\title{
Time-course of functional and pathological changes after a single high acute inhalation of chlorine in rats
}

\author{
R. Demnati*,+, R. Fraser**, H. Ghezzo*,+, J.G. Martin+, G. Plaa++, J.L. Malo*
}

Time-course of functional and pathological changes after a single high acute inhalation of chlorine in rats. R. Demnati, R. Fraser, H. Ghezzo, J.G. Martin, G. Plaa, J.L. Malo. (OERS Journals Ltd 1998.

ABSTRACT: Reactive airways dysfunction syndrome (RADS) is an asthma-like condition that follows exposure to very high concentrations of an irritant material. We assessed the time-course of pathophysiological alterations in a model of RADS.

Sprague-Dawley rats were exposed to 1,500 parts per million $(\mathbf{p p m})$ of chlorine for $5 \mathrm{~min}$. Lung resistance $(R \mathrm{~L})$, responsiveness to inhaled methacholine (MCh), the airway epithelium and bronchoalveolar lavage (BAL) were assessed over a 3 month period after exposure.

$R L$ increased significantly up to 3 days after exposure, reaching a maximal change of $110 \pm 16 \%$ from baseline. There was a significant decrease in the concentration of MCh required to increase $R \mathrm{~L}$ by $0.20 \mathrm{cmH}, \mathrm{O} \cdot \mathrm{mL}^{-1 \cdot} \cdot \mathrm{s}$ from days 1-7 after exposure. In some rats, MCh hyperresponsiveness and $R \mathrm{~L}$ changes persisted after exposure for as long as 1 and 3 months, respectively. Histological evaluation with morphometric evaluation revealed epithelial flattening, necrosis, increase in smooth muscle mass and evidence of epithelial regeneration. BAL showed an increased number of neutrophils. The timing of maximal abnormality in the appearance of the epithelium (days 1-3) corresponded to that of the maximal functional changes.

Acute high chlorine exposure results in functional and pathological abnormalities that resolve in the majority of animals after a variable period; however, these changes can persist in some animals. Functional abnormalities in the initial stages may be related to airway epithelial damage.

Eur Respir J 1998; 11: 922-928.
*Dept of Chest Medicine, Hôpital du Sacré-Coeur, **Dept of Pathology, ${ }^{+}$Meakins-Christie Laboratories, McGill University, ${ }^{++}$Dept of Pharmacology, Université de Montréal, Montreal, Canada.

Correspondence: J.L. Malo

Dept of Chest Medicine

Hôpital du Sacré-Coeur

5400 West Gouin

Montreal H4J 1C5

Canada

Fax: 51433831231

Keywords: Acute lung injury

occupational asthma

reactive airways dysfunction syndrome

Received: March 241997

Accepted after revision December 201997

This work was partially supported by the Centre Québécois d'Excellence en Santé Respiratoire and by the Canadian Network of Toxicology Centres.
Acute exposure to a high level of an irritant substance can induce reactive airways dysfunction syndrome (RADS); an asthma-like illness with nonallergenic hyperresponsiveness (NAHR). Symptoms that mimic asthma (cough, dyspnoea, wheezing) develop within minutes or hours of a single exposure in a previously healthy individual and can persist in association with bronchial hyperresponsiveness for $\breve{S} 1$ yrs after the exposure [1]. The diagnosis of RADS is made retrospectively and the subjects are rarely investigated before and serially after irritant exposure. The physiopathological mechanism of RADS is, thus, still speculative and is usually attributed to neurogenic inflammation caused by release of airway tachykinins [2].

Chlorine gas is one of the main causal agents of irritantinduced asthma but has received little attention compared to other lung irritant products, considered as environmental air pollutants such as oxides of sulphur or nitrogen and acid aerosols [3]. Residual pulmonary effects of acute high chlorine exposure have been inconsistently observed in early studies [4-6], but recent data have shown that airflow limitation, NAHR, a mucosal inflammatory infiltrate (mostly lymphocytes), and a thickening of the epithelial basement membrane may persist in some cases [7-12]. However, the interpretation of the findings from human studies are limited because of the paucity of histopatho- logical material, the difficulty of performing serial evaluation of lung injury, and the potential role of the other risk factors on the long-term sequelae of chlorine gas exposure.

The precise pattern of airway injury and repair following exposure to high level of irritant products known to cause RADS are poorly understood. Therefore, we felt that using an animal model of this condition [13] had substantial potential to further our understanding of RADS, as the serial assessment of pathological and functional abnormalities cannot easily be done in humans. Thus, the purpose of the present study was to document the timecourse of functional and pathological changes and the relationship between these findings in Sprague-Dawley rats exposed once to a high concentration of chlorine.

\section{Materials and methods}

\section{Animals}

Sprague-Dawley male rats (225-250 g) were purchased from Charles River (St-Constant, Quebec, Canada) and housed in a conventional animal care facility at the University of Montreal before experimentation. The animals consisted of a control group $(n=8)$ and 56 exposed rats 
divided into seven groups according to the timing of histological evaluation, were studied. An additional group of exposed rats $(n=16)$ was used for analysis of bronchoalveolar lavage (BAL). The control rats were placed in the chamber for a similar duration but they breathed only compressed air and were sacrificed as untreated controls for histological examination. BAL analysis was performed before exposure and at each time-interval over a 3 month period (at each time point, two animals were lavaged). The protocol was approved by the Animal Ethics Committee at the University of Montreal.

\section{Chlorine exposure}

The rats were exposed in a flow-past chamber with nose-only exposure [14]. The chamber has six ports and as such a maximum of six rats could be simultaneously exposed. Approximately $7 \mathrm{~s}$ are required to reach the full chlorine concentration at a flow of $2 \mathrm{~L} \cdot \mathrm{min}^{-1}$. After each exposure, the flow is increased to achieve clearance in approximately $2 \mathrm{~s}$ and the extracted airflow is passed through a sodium bicarbonate solution to neutralize chlorine. Chlorine was obtained from a gas cylinder containing 1,500 parts per million (ppm) chlorine in a mixture of $80 \% \mathrm{~N}_{2}$ and $20 \% \mathrm{O}_{2}$ (Aldrich Chemical Company Inc., Milwaukee, WI, USA). The average coefficient of variation of the level of chlorine exposure was $<10$. This was determined from 10 repeated chlorine exposures to different concentrations obtained from a gas cylinder containing $99.5 \%$ chlorine (Aldrich Chemical Company Inc.) and diluted with air to achieve the chlorine concentration required (20-200 ppm) which was measured continuously using a chlorine monitor (PortSens Gas Detector, Analytical Technology Inc., Conshohochen, PA, USA).

\section{Experimental design}

In the flow-past chamber rats were exposed to 1,500 ppm of chlorine gas for $5 \mathrm{~min}$. Chlorine exposure to 1,500 ppm for $5 \mathrm{~min}$ has been previously found to induce airway mucosal abnormalities with minimal mortality [13]. In exposed rats, physiological evaluation was performed 2 days prior to exposure and at 1,2, 3, 7, 14, 30 and 90 days after exposure. Following physiological assessment, eight rats were sacrificed at each time-interval for histological evaluation with morphometric measurements (see below). BAL analysis was performed before exposure and at each time interval after exposure.

\section{Measurement of lung resistance $(\mathrm{R} L)$}

$R \mathrm{~L}$ was measured during spontaneous breathing as previously described [15]. The rats were placed in the left lateral decubitus position with the end of the endotracheal tube inside a small plexiglass box (volume $265 \mathrm{~mL}$ ). A Fleisch No. 0 pneumotachograph (Bionetics Limited, Quebec, Canada) coupled to a differential transducer (MP -45 $\pm 2 \mathrm{cmH}_{2} \mathrm{O}$; Validyne Corp., Northridge, CA, USA) was attached to the box to measure airflow. Changes in oesophageal pressure were measured using a saline-filled catheter and a differential pressure transducer (Sanborn 267 BC; Hewlett-Packard, Waltham, MA, USA). The other port of the transducer was connected to the box. The oesophageal catheter consisted of a $20 \mathrm{~cm}$ length of PE240 polyethylene tubing attached to a $6 \mathrm{~cm}$ length of PE100 tubing that was advanced into the oesophagus of the rat until a clear cardiac artifact was discernible. Transpulmonary pressure $(P \mathrm{tp})$ was computed as the difference between oesophageal and box pressures. Airway responses were evaluated from $R \mathrm{~L}$ which was determined by multiple linear regression, fitting the equation:

$$
P \mathrm{tp}=E \mathrm{LV}+\mathrm{RL} V^{\prime}+\mathrm{K} \text { to } 10 \mathrm{~s} \text { segments of data }
$$

where $V^{\prime}$ is flow, $\mathrm{V}$ is volume, EL is elastance of the lung, and $\mathrm{K}$ is a constant value using a commercial software package (RHT INFODAT Inc., Montreal, Quebec, Canada). $R \mathrm{~L}$ measurements were made without subtraction of the resistance of the endotracheal tube.

\section{Airway responsiveness to methacholine (MCh)}

Rats were anaesthetized i.p. with pentobarbital sodium $\left(30 \mathrm{mg} \cdot \mathrm{kg}^{-1}\right)$ and xylazine $\left(7 \mathrm{mg} \cdot \mathrm{kg}^{-1}\right)$ and treated as described for the measurement of $R \mathrm{~L}$. Supplemental injections of pentobarbital $\left(5 \mathrm{mg} \cdot \mathrm{kg}^{-1}\right.$, i.p. $)$ were administered when it was necessary to prolong anaesthesia. After initial measurement of $R \mathrm{~L}$ during spontaneous breathing, the rats were given aerosols of phosphate-buffered saline (PBS) and progressively doubling concentrations ranging $0.063-$ $16 \mathrm{mg} \cdot \mathrm{mL}^{-1}$ of aerosolized $\mathrm{MCh}$ until a doubling in $R \mathrm{~L}$ was obtained. In order to correct for changes in airway calibre after each concentration, responsiveness to $\mathrm{MCh}$ is expressed as the effective concentration of $\mathrm{MCh}$ required to induce increase in $R \mathrm{~L}$ of $0.20 \mathrm{cmH}_{2} \mathrm{O} \cdot \mathrm{mL}^{-1}$.s from postsaline inhalation value $(\mathrm{EC} \Delta R \mathrm{~L})$, this being obtained from the dose-response curve drawn on a semilogarithmic graph and expressed as log EC $\Delta R \mathrm{~L}$. The peak value of $R \mathrm{~L}$ was measured before and after inhalation of saline and after each concentration of MCh [16]. An interval of 3 min elapsed between the administrations of the MCh concentrations. Aerosols were generated from $3 \mathrm{~mL}$ of solution using a Hudson nebulizer (Model 1400; Hudson, Temecula, CA, USA) with an airflow of $10 \mathrm{~L} \cdot \mathrm{min}^{-1}$; each administration lasted for $30 \mathrm{~s}$.

\section{Histological examination}

At the time of sacrifice, animals were anaesthetized with pentobarbital sodium (30 mg.kg-1 i.p.) and xylazine ( $7 \mathrm{mg} \cdot \mathrm{kg}^{-1}$ i.p.) and the chest wall was opened. The trachea was tied off and the lungs removed en bloc and fixed by intratracheal injection using a syringe until full inflation was reached $(2-4 \mathrm{~mL})$. This was followed by immersion in $10 \%$ formalin for $24-48 \mathrm{~h}$. Slices from each lung were taken in the parasagittal plane, embedded in paraffin and processed routinely with haematoxylin-eosin stain, periodic acid-Schiff (PAS) and haematoxylin-phloxine-saffron (HPS) stains for microscopic examination and morphometric measurements. The presence of airway epithelial damage (necrosis, detachment from the basement membrane) and regeneration (stratification with nuclear enlargement, and mucous cell hyperplasia) and morphometric measurements were determined by one observer in a blind fashion. In order to quantify the effects of chlorine on airway structure, microscopic images were traced using a drawing tube attachment to the microscope (Leitz Wetzlar, 
Wetzlar, Germany); images were then digitized using commercial software (Sigma Scan; Jandel Scientific, corte Madera, CA, USA). The length of airway epithelium that was flattened, necrotic or detached from the basement membrane or that showed nuclear stratification (multilayering) was measured and expressed as a percentage of the total basement membrane length of the airways. PAS positive mucus secreting cells were counted directly. The following morphometric measurements were made on the airways from HPS stained slides in a control group and at 3,14 and 90 days after exposure according to recently proposed nomenclature [17]: basement membrane perimeter $(\mathrm{Pbm})$, the luminal area defined by the basement membrane $(\mathrm{Abm})$, the internal perimeter (luminal border of epithelium), and the outer perimeter (outer border of adventitia). The area circumscribed by the internal surface of the airway epithelium (Ai) and by the external border of the airway wall (Ae) was also measured. The areas of the airway epithelium (EA) and the airway wall (WA) were calculated as the difference between Abm and the Ai and between Ae and Abm, respectively. We normalized EA and WA to the relaxed area (Ar) to adjust for differences in airway size. The ideal area of the lumen of the relaxed airway was calculated as:

$$
\mathrm{Ar}=(\mathrm{Pbm})^{2} / 4 \pi
$$

The quantity of airway smooth muscle was calculated as the areas of the airway wall occupied by smooth muscle divided by $(\mathrm{Pbm})^{2}$ in order to standardize for airway size. To assess whether airways were cut in cross section, we measured the maximal diameter of the airway (D1) and the diameter at the widest point perpendicular to this axis (D2). We analysed airways with a ratio of D2/D1 $>0.33$. The size of the airways that were measured was mean (range) $1.30 \mathrm{~mm}(0.36-2.81)$. Five airways were examined for each rat.

Intra-observer variance of the basement membrane length was examined by repeated measurements of randomly chosen airways that were made on separate days by the same observer. Inter-observer variance was tested by comparing the measurements of two observers on six randomly chosen airways. The intra-observer coefficient of variation was $<5 \%$; the largest observed difference was $0.01 \mathrm{~mm}$, the mean being $0.005 \mathrm{~mm}$ and the SD $0.17 \mathrm{~mm}$. The inter-observer correlation coefficient was $>0.98$ ( $\mathrm{p}<$ 0.001 ) and the mean difference between observers was $<3 \%$ of the measured mean value. The largest observed difference was $0.03 \mathrm{~mm}$, the mean being $0.001 \mathrm{~mm}$ and the SD $0.005 \mathrm{~mm}$.

\section{$B A L$}

BAL was performed in anaesthetized and intubated rats before exposure and at 1, 2, 3, 7, 14, 30, and 90 days after exposure in two separate animals on each occasion. The lungs were lavaged through the endotracheal tube by five instillations of $5 \mathrm{~mL}$ of saline at room temperature. After the five repeated instillations of $5 \mathrm{~mL}$ of saline at each time, the animals were sacrificed. After filtration, the fluid was cytocentrifuged at 2,000 revolutions per minute (rpm) for $10 \mathrm{~min}$, decanted and suspended in $5 \mathrm{~mL}$ of PBS. The total cell count was determined on a fresh specimen of lavage fluid using a haemacytometer. Trypan blue exclu- sion for viability was performed. The cell differentials were obtained by counting at least 300 cells on a glass cover preparation stained with Diff-Quik (Baxter Healthcare Corp., Scientific Div., Miami, FL, USA).

\section{Data analysis}

In the physiological study, we used Dunnett's test of multiple treatments versus a common control, testing the difference between each time point value and the common baseline, i.e., each rat was referred to its own control value at baseline. In the pathological study, an analysis of variance followed by the Dunnett's test of multiple comparisons (times) versus the common control condition (before exposure) was used, since all the rats were different. All results are expressed as mean \pm SEM. Differences were considered to be statistically significant when p-values were $<0.05$.

\section{Results}

\section{Physiological assessment}

Acute exposure to a high concentration of chlorine gas caused an increase in $R \mathrm{~L}$ up to $72 \mathrm{~h}$ after exposure (fig. 1a) and enhanced responsiveness to MCh up to 7 days after
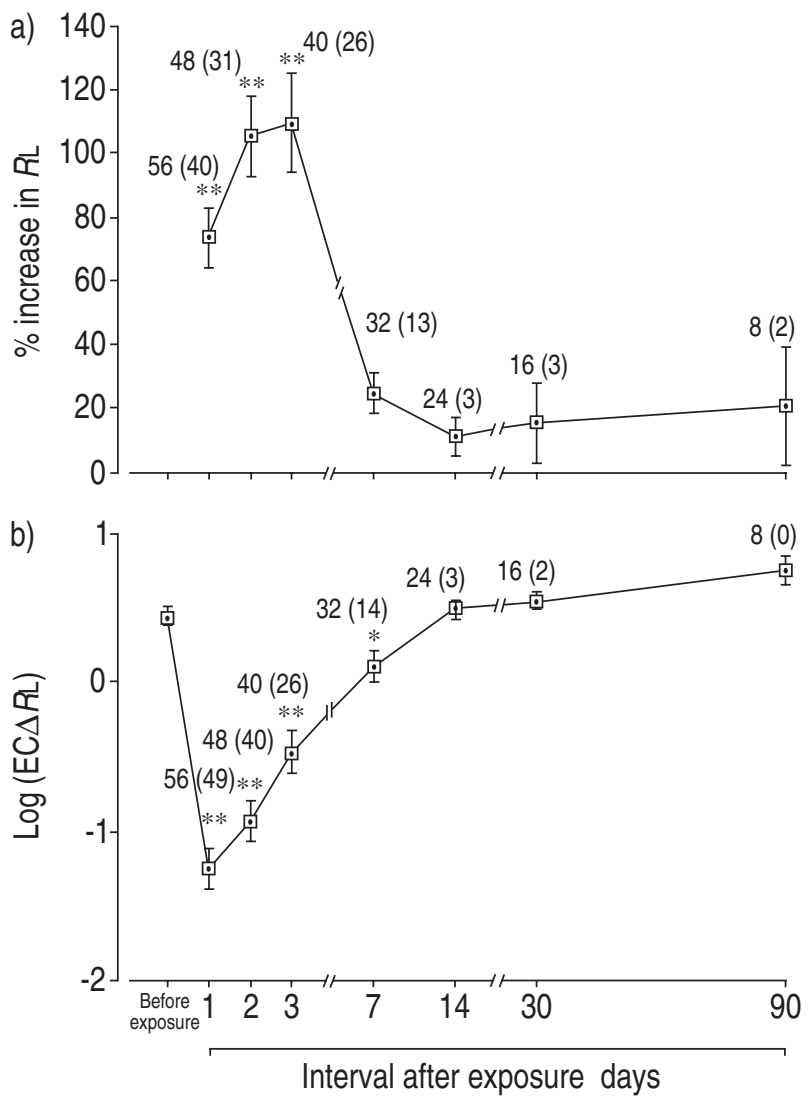

Fig. 1. - a) Time-course of lung resistance $(R \mathrm{~L})$ changes after acute chlorine exposure; b) time-course of the effective concentration of methacholine required to induce an increase in $R \mathrm{~L}$ of $0.20 \mathrm{cmH}_{2} \mathrm{O} \cdot \mathrm{mL}^{-1}$. $\mathrm{s}$ from post-saline inhalation value $(\mathrm{EC} \Delta R \mathrm{~L})$. Data are expressed as mean \pm SEM. The total number of animals and the number of animals with abnormal findings in parenthesis are given at each time interval. ***: $\mathrm{p}<0.05, \mathrm{p}<0.01$, comparing measured values versus baseline values. 
exposure as evidenced by a decrease in the MCh concentration required to induce an increase in lung resistance $\left(\Delta R \mathrm{~L}\right.$ ) from the baseline value of $0.20 \mathrm{cmH}_{2} \mathrm{O} \cdot \mathrm{mL}^{-1} \cdot \mathrm{s}$ (fig. $1 b)$. Our data also indicate that some rats remained abnormal up to 30 and 90 days after exposure. Abnormal rats were defined as those animals whose $R \mathrm{~L}$ or responsiveness to MCh was greater than their baseline values plus 2sD; the latter was determined during the testing of reproducibility in the beginning of the study and consisted of five repeated measurements of $R \mathrm{~L}$ and $\mathrm{MCh}$ challenge tests performed weekly in four air-exposed rats (200-250 g, 6 weeks old). Hyperresponsiveness persisted up to 30 days in 2 of 16 rats (fig. 1b) and increased $R$ L persisted up to 90 days after chlorine exposure in 2 of 8 rats (fig. 1a). Table 1 shows that the $R \mathrm{~L}$ and bronchial responsiveness values were highly reproducible in these eight animals after the initial increase.

\section{Pathological assessment}

Histological examination from samples obtained $24 \mathrm{~h}$ after exposure showed severe injury to the bronchial epithelium, as evidenced by flattening, detachment from the basement membrane and necrosis (fig. 2). Evidence of epithelial regeneration (stratification) was present one day after exposure, reached a maximum 3 days after exposure and remained significantly elevated 7 days after exposure (fig. 3). The number of mucus-secreting cells rose 7 days after exposure, reached a maximum at 14 days and was still significantly increased 30 days after exposure (fig. 4). The proportion of bronchial epithelium length without any specific alterations (i.e., epithelial flattening, necrosis, and stratification) was $0 \%$ on days $1-3,40 \%$ on day $7,72 \%$ on day $14,92 \%$ on day 30 and $96 \%$ on day 90 .

Morphometric measurements showed that the mean quantity of SM was approximatively three times greater in the exposed group as compared to the control group on day 3 after exposure (table 2).

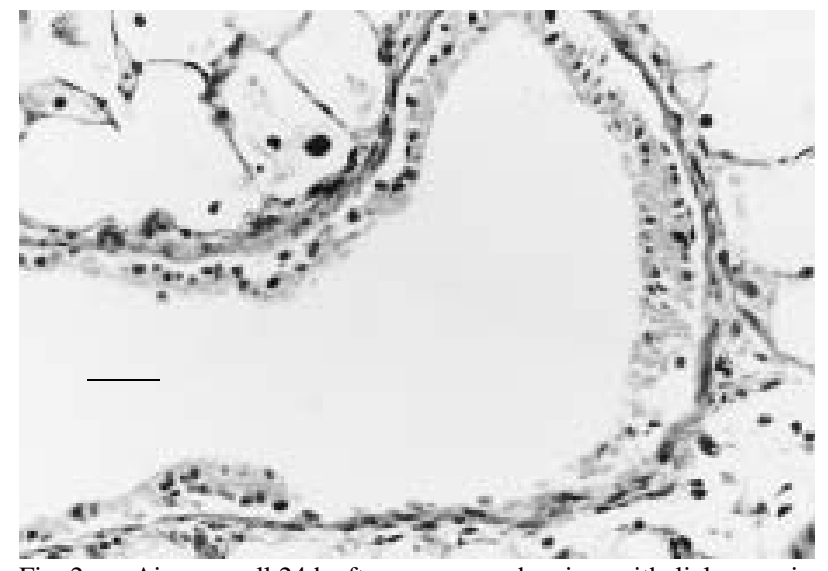

Fig. 2. - Airway wall $24 \mathrm{~h}$ after exposure, showing epithelial necrosis. Internal scale bar $=75 \mu \mathrm{m}$

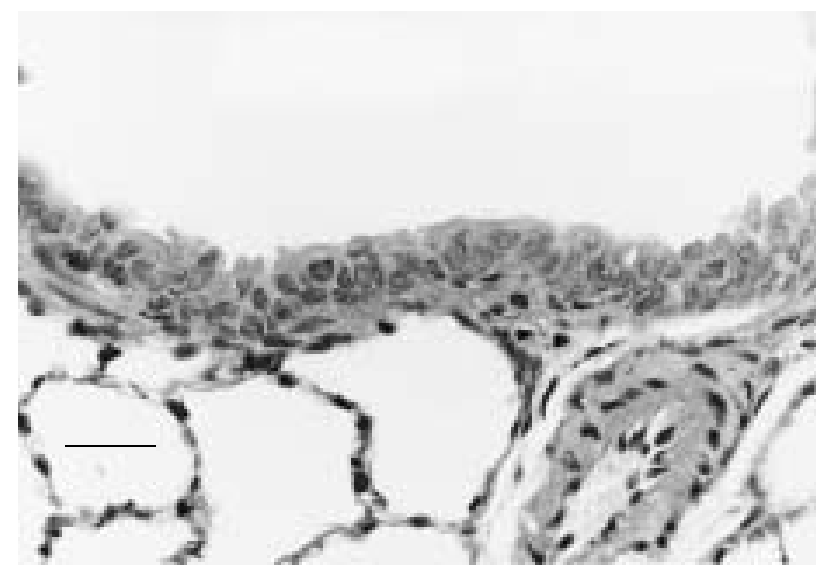

Fig. 3. - Airway wall 3 days after exposure, showing evidence of regeneration manifested by epithelial stratification. Internal scale bar= $25 \mu \mathrm{m}$.

Table 1. - Functional data obtained before exposure and over a 3 month period after a single exposure to chlorine in eight rats

\begin{tabular}{|c|c|c|c|c|c|c|c|c|c|}
\hline \multirow[b]{2}{*}{$\begin{array}{l}\text { Animal } \\
\text { No. }\end{array}$} & \multirow[b]{2}{*}{$\begin{array}{c}\text { Functional } \\
\text { data }\end{array}$} & \multirow[b]{2}{*}{$\begin{array}{l}\text { Before } \\
\text { exposure }\end{array}$} & \multicolumn{7}{|c|}{ Interval after exposure days } \\
\hline & & & 1 & 2 & 3 & 7 & 14 & 30 & 90 \\
\hline \multirow[t]{2}{*}{1} & $R \mathrm{~L}$ & 0.209 & 0.170 & 0.230 & 0.321 & 0.163 & 0.162 & 0.195 & 0.155 \\
\hline & $\mathrm{EC} \Delta R \mathrm{~L}$ & 8.40 & saline & 0.25 & 1.41 & 1.61 & 8.0 & 7.01 & 9.84 \\
\hline \multirow[t]{2}{*}{$2 *$} & $R \mathrm{~L}$ & 0.098 & 0.225 & 0.188 & 0.140 & 0.175 & 0.168 & 0.195 & 0.182 \\
\hline & $\mathrm{EC} \Delta R \mathrm{~L}$ & 7.67 & 0.66 & 1.79 & 2.58 & 3.92 & 3.14 & 3.84 & 9.86 \\
\hline \multirow[t]{2}{*}{$3^{*+}$} & $R \mathrm{~L}$ & 0.105 & 0.239 & 0.321 & 0.330 & 0.177 & 0.172 & 0.229 & 0.206 \\
\hline & $\mathrm{EC} \Delta R \mathrm{~L}$ & 6.10 & saline & 0.80 & 1.90 & 2.58 & 2.50 & 2.58 & 5.19 \\
\hline \multirow[t]{2}{*}{4} & $R \mathrm{~L}$ & 0.250 & 0.306 & 0.300 & 0.320 & 0.213 & 0.278 & 0.268 & 0.172 \\
\hline & $\mathrm{EC} \Delta R \mathrm{~L}$ & 2.75 & saline & 0.90 & 2.02 & 2.10 & 5.58 & 2.53 & 2.31 \\
\hline \multirow[t]{2}{*}{$5^{+}$} & $R \mathrm{~L}$ & 0.114 & 0.327 & 0.259 & 0.269 & 0.184 & 0.177 & 0.215 & 0.184 \\
\hline & $\mathrm{EC} \Delta R \mathrm{~L}$ & 5.60 & saline & saline & saline & 4.79 & 5.28 & 7.41 & 7.57 \\
\hline \multirow[t]{2}{*}{6} & $R \mathrm{~L}$ & 0.290 & 0.365 & 0.280 & 0.573 & 0.479 & 0.300 & 0.170 & 0.231 \\
\hline & $\mathrm{EC} \Delta R \mathrm{~L}$ & 1.41 & saline & 0.19 & 0.57 & 2.75 & 4.69 & 5.06 & 2.44 \\
\hline \multirow[t]{2}{*}{7} & $R \mathrm{~L}$ & 0.224 & 0.415 & 0.278 & 0.236 & 0.319 & 0.319 & 0.268 & 0.214 \\
\hline & $\mathrm{EC} \Delta R \mathrm{~L}$ & 2.66 & 1.95 & 2.32 & 5.52 & 4.96 & 2.62 & 4.31 & 7.16 \\
\hline \multirow[t]{2}{*}{8} & $R \mathrm{~L}$ & 0.235 & 0.302 & 0.693 & 0.441 & 0.249 & 0.253 & 0.204 & 0.252 \\
\hline & $\mathrm{EC} \Delta R \mathrm{~L}$ & 4.35 & saline & saline & saline & 0.93 & 5.27 & 3.45 & 6.10 \\
\hline
\end{tabular}

$R \mathrm{~L}$ : lung resistance $\left(\mathrm{cmH}_{2} \mathrm{O} \cdot \mathrm{mL}^{-1} \cdot \mathrm{s}\right)$; EC $\Delta R \mathrm{~L}$, effective concentration of methacholine (MCh) required to induce an increase in $R \mathrm{~L}$ of $0.20 \mathrm{cmH}_{2} \mathrm{O} \cdot \mathrm{mL}^{-1} \cdot \mathrm{s}$ above post-saline inhalation value $\left(\mathrm{mg} \cdot \mathrm{mL}^{-1}\right)$; saline: $R \mathrm{~L}$ values doubled from baseline under saline inhalation. *: increased responsiveness to $\mathrm{MCh}$ at each time interval over 1 month after exposure; ${ }^{+}: R \mathrm{~L}$ remained elevated at each time interval over the 3 month period. 


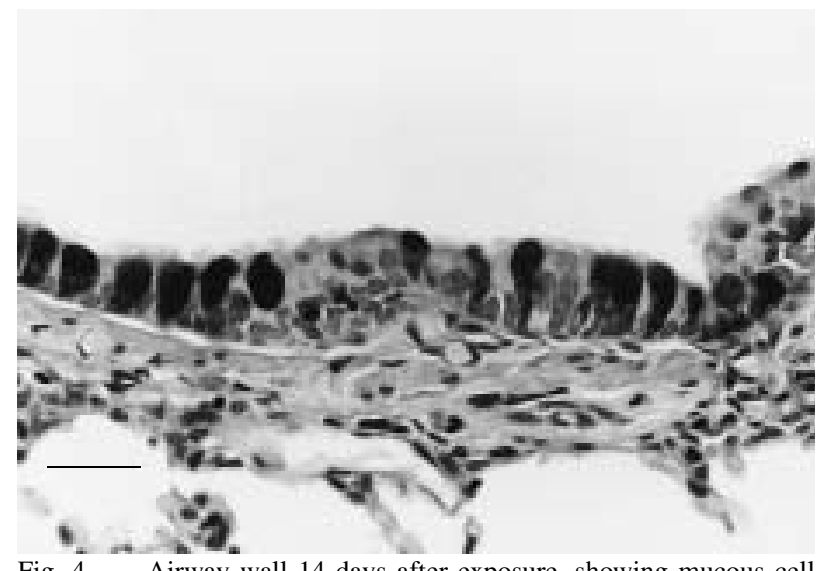

Fig. 4. - Airway wall 14 days after exposure, showing mucous cell hyperplasia. Internal scale bar $=20 \mu \mathrm{m}$.

BAL was analysed for total cell count, total cells per millilitre of fluid and percentage distribution of each type of cell. Cell viability was greater than $84 \%$ in all rats as assessed by trypan blue exclusion. Although the number of rats studied at each time $(n=2)$ was not large enough for reliable statistical comparison, it appears that chlorine exposure was associated with an increase in the total number of cells soon after exposure. This increase was the result of an increase in neutrophils (table 3).

Correlations between functional and pathological changes

To compute the correlations between functional and pathological measurements, since they were performed on different animals (two for BAL and a variable number for the functional value (56 at time 1 to eight at time 8)), we took the mean value at each time as the measurement at that time point. Thus, correlations were computed with 7 pairs of functional BAL values.

The period during which the maximal changes were observed in bronchial epithelium (days 1-3) corresponded to the timing of maximal changes in functional indices. However, there was no significant correlation between any specific epithelial alteration (e.g., epithelial flattening, necrosis or stratification) and either $R \mathrm{~L}$ or responsiveness to $\mathrm{MCh}$. There was a significant correlation $(\mathrm{p}=0.0001)$ between mean $R \mathrm{~L}$ and mean BAL neutrophilia all time ( $\mathrm{r}=$ $0.98)$.

\section{Discussion}

The present study demonstrates that acute exposure to high concentrations of chlorine gas induces pathological and functional changes in the lungs of Sprague-Dawley rats. Histological changes consisted of epithelial necrosis and detachment, increase in the area of smooth muscle, epithelial regeneration and mucous cell hyperplasia. Most of these abnormalities resolved after a mean interval of 90 days. Functional changes (increased $R \mathrm{~L}$ and/or bronchial responsiveness to inhaled $\mathrm{MCh}$ ) lasted for mean intervals of 3 and 7 days after exposure, but persisted up to 30 and 90 days, respectively, in some animals. The functional changes were related to the overall abnormal airway epithelial damage and there was a significant correlation between $R \mathrm{~L}$ and BAL neutrophilia.

Although evidence of lung damage after chlorine exposure was first suspected clinically in World War I soldiers [18] and confirmed by pathological examination of experimental animals in 1920 [19], pathological descriptions from human material following acute exposure to a high level of an irritant material are rare. Most of these studies

Table 2. - Morphometric results in rat lung exposed to 1,500 parts per million (ppm) of chlorine for 5 min

\begin{tabular}{lcccc}
\hline & & \multicolumn{3}{c}{ Interval after exposure days } \\
\cline { 3 - 5 } & Control & 3 & 14 & 90 \\
\hline rats & 8 & 8 & 8 & 8 \\
Airways $n$ & 40 & 40 & 40 & 40 \\
SM $10^{-4}$ & $6.25 \pm 0.91$ & $16.77 \pm 9.80$ & $6.39 \pm 0.40$ & $6.07 \pm 0.68$ \\
EA/Ar & $0.125 \pm 0.012$ & $0.131 \pm 0.011$ & $0.154 \pm 0.014$ & $0.119 \pm 0.007$ \\
WA/Ar & $0.446 \pm 0.049$ & $0.459 \pm 0.042$ & $0.425 \pm 0.035$ & $0.448 \pm 0.026$ \\
\hline
\end{tabular}

Values are presented as mean \pm SEM of rats' mean (mean of five airways for each rat). Control rats were exposed to compressed air. SM: quantity of smooth muscle; EA: area of airway epithelium; Ar: ideally relaxed area; WA: airway wall area.

Table 3. - Cell counts in bronchoalveolar lavage obtained before and after a single exposure to chlorine

\begin{tabular}{|c|c|c|c|c|c|c|c|c|}
\hline \multirow[b]{2}{*}{ Cell type } & \multirow[b]{2}{*}{$\begin{array}{l}\text { Before } \\
\text { exposure }\end{array}$} & \multicolumn{7}{|c|}{ Interval after exposure days } \\
\hline & & 1 & 2 & 3 & 7 & 14 & 30 & 90 \\
\hline \multirow[t]{2}{*}{ Total cells $\times 10^{6}$} & 4.0 & 3.8 & 6.6 & 6.4 & 2.5 & 2.2 & 4.5 & 2.6 \\
\hline & 2.9 & 6.6 & 15.0 & 8.2 & 1.3 & 2.4 & 2.8 & 3.5 \\
\hline \multirow[t]{2}{*}{ Neutrophils \% } & 0 & 26 & 20 & 43 & 10 & 0 & 1 & 3 \\
\hline & 0 & 46 & 55 & 47 & 0 & 1 & 1 & 1 \\
\hline \multirow{2}{*}{ Macrophages \% } & 100 & 67 & 75 & 51 & 74 & 99 & 95 & 95 \\
\hline & 98 & 49 & 40 & 47 & 88 & 98 & 93 & 97 \\
\hline \multirow[t]{2}{*}{ Lymphocytes \% } & 0 & 6 & 5 & 6 & 16 & 1 & 4 & 2 \\
\hline & 2 & 2 & 5 & 6 & 12 & 1 & 6 & 2 \\
\hline
\end{tabular}

Total cell number and differential cell counts. At each time point two animals were investigated i.e., 16 animals in the entire experiment. 
are retrospective and data originate from biopsies performed 1-6 yrs after single or repeated exposure. BRooKs et al. [1] first described RADS and reported the presence of bronchial wall inflammation (mostly lymphocytes and plasma cells with no eosinophils), desquamation of respiratory epithelium in one biopsy and goblet cell hyperplasia in another. Deschamps et al. [9, 20] performed biopsies several months after exposure to sodium hypochlorite and hydrochloric acid. They reported similar findings: epithelial destruction associated with a mild inflammatory reaction (predominantly lymphocytes with no eosinophils) and subepithelial fibrosis without thickening of the basement membrane. Histological evaluation over a 5 month period after acute and massive exposure has recently been reported by LeMIËRE and co-workers [10-12] in three subjects exposed to chlorine gas, isocyanates, and urea fumes, respectively. They found epithelial desquamation and an inflammatory infiltrate (mostly T-lymphocytes) followed by subepithelial fibrosis and epithelial regeneration. The patients were given inhaled steroids at day 3 after exposure in the first case and at 46 and 60 days, respectively, in the two other cases.

We have previously reported that inhalation of a single high dose of chlorine results in extensive histological changes in rat lungs, including airspace oedema, epithelial sloughing and necrosis, a mild inflammatory mucosal reaction (polymorphonuclear leukocytes) and evidence of epithelial regeneration, as assessed at 1, 3, 6, 12, 24 and $72 \mathrm{~h}$ after exposure [13]. Our present data extend these observations to 90 days after exposure. To our knowledge, this is the first study that has examined functional and histological changes with morphometric measurements and bronchoalveolar analysis after a single and massive chlorine exposure. The lung parenchyma in our rats was not significantly affected. In contrast to the experiment by MeULENBELT et al. [21], in which the animals experienced a high incidence of alveolar oedema, an increase in the number of alveolar macrophages and neutrophilic leukocytes, and interstitial thickening of the centriacinar septa, one day after a $10 \mathrm{~min}$ exposure to $\mathrm{NO}_{2}$ at $175 \mathrm{ppm}$. More recently, ТочА et al. [22] showed epithelial desquama-tion, goblet cell hyperplasia, perivascular inflammatory cells and alveolar space oedema followed by the development of fibrosis in the alveolar duct. In contrast to the ex-periments of TоYа et al. [22], in which rats were exposed to nickel fumes at a single dose of $14.3 \mathrm{mg} \cdot \mathrm{kg}^{-1}$, which caused $4 \%$ mortality and the development of fibrosis in alveolar ducts, the lungs of our rats were not significantly affected and the exposure did not induce mortality. Our intention was to evoke airway changes, while preserving peripheral lung structures, in order to replicate the events leading to RADS in humans. Moreover, although we have evaluated only a small number of airways in each rat at 3 , 14 and 90 days after exposure, the SM quantity seemed to be affected by chlorine exposure.

The present study also provides information on the time-course of airway responsiveness and $R \mathrm{~L}$. Although we have studied only a small number of rats (eight rats) over a 3 month period, there is evidence that increased $R \mathrm{~L}$ persisted in two out of eight animals, at all times studied over the 3 months following the initial exposure. Normally lung volumes and airflows increase over time during the growth of rats. The decrease in airflow associated with ageing is only found after 8-12 months in Sprague-
Dawley rats that initially weighed 400-510 g [23]. In the present study, rats weighing 200-250 g, were used and studied over a 3 month period. Thus, in view of the reproducibility of repeated measures of $R \mathrm{~L}$ and airway responsiveness found in normal animals, the changes in $R \mathrm{~L}$ that we observed are likely to be related to chlorine exposure. Similar reproducibility has been reported by BeLLOFORE and MARTIN [24] despite repeated anaesthesias and intubation procedures. It is not entirely clear whether these functional abnormalities are directly due to chlorine exposure or whether they resulted from other causes, such as infection, especially if we consider that increased susceptibility to infection is a well known phenomenon in chlorine exposed animals [3]. We have no explanation for the fact that the two rats with increased $R \mathrm{~L}$ did not show increased bronchial hyperresponsiveness at the 3 month assessment. We previously described one human subject with RADS, abnormal forced expiratory volume in one second (FEV1) but normal bronchial responsiveness [25]. This functional limitation is similar to those described in some humans, in whom airflow obstruction and/or nonspecific bronchial hyperresponsiveness have been reported to persist months to years following massive toxic gas exposure $[1,7,26-$ 28]. Epithelial damage consisting in epithelial detachment and necrosis was maximal during the first $24 \mathrm{~h}$ after exposure, at the same time as the maximal hyperresponsiveness. Epithelial shedding is correlated to bronchial responsiveness [29] and the degree of bronchial hyperresponsiveness is proportional to the extent of denudation of the basement membrane [30]. $R$ L reached its maximum increase at the same time as peak of neutrophilia in BAL. Recent human data collected over a 1-7 yr period from victims of massive exposure to methyl isocyanates in Bhopal showed that the neutrophil count in BAL was negatively correlated with the obstructive ventilatory defect [31]. Increased $R \mathrm{~L}$ persisted up to 90 days after exposure in two out of eight animals sacrificed. At this time, the epithelium, the airway wall area, and the quantity of smooth muscle were almost normal suggesting that the persisting obstruction could not be attributed to structural changes but rather to the presence of inflammatory mediators within airway tissue.

This study demonstrates that following a single chlorine exposure the Sprague-Dawley rat develops changes in the airways compatible with the lesions anticipated in reactive airways dysfunction syndrome. While acute functional changes are related to airway structural changes, this does not seem to be the case for persistent increase in lung resistance, because this occurred in selected animals only. Further investigation of epithelial and smooth muscle structure may help elucidate the mechanism of the persistent altered pulmonary mechanics.

Acknowledgements: The authors acknowledge B. Murray and L. Pineau for the technical assistance and L. Schubert for reviewing the manuscript.

\section{References}

1. Brooks SM, Weiss MA, Bernstein IL. Reactive airways dysfunction syndrome (RADS); persistent asthma syndrome after high level irritant exposures. Chest 1985; 88: 376-384. 
2. Brooks SM, Bernstein IL. Reactive airways dysfunction syndrome or irritant-induced asthma. In: Asthma in the Workplace. Bernstein IL, Chan-Yeung M, Malo JL, Bernstein DI, eds. New York, Marcel Dekker Inc., 1993; pp. 533-549.

3. Das R, Blanc PD. Chlorine gas exposure and the lung: a review. Toxicol Ind Health 1993; 9: 439-455.

4. Hasan FM, Geshman A, Fuleihan FJD. Resolution of pulmonary dysfunction following acute chlorine exposure. Arch Environ Health 1983; 38: 76-80.

5. Charan NB, Lakshminarayan S, Myers GC, Smith DD. Effects of accidental chlorine inhalation on pulmonary function. West J Med 1985; 143: 333-336.

6. Jones RN, Hughes JM, Glindmeyer H, Weill H. Lung function after acute chlorine exposure. Am Rev Respir Dis 1986; 134: 1190-1195.

7. Schwartz DA, Smith DD, Lakshminarayan S. The pulmonary sequelae associated with accidental inhalation of chlorine gas. Chest 1990; 97: 820-825.

8. Gautrin D, Boulet L-P, Boutet M, et al. Is reactive airways dysfunction syndrome (RADS) a variant of occupational asthma? J Allergy Clin Immunol 1994; 93: 12-22.

9. Deschamps D, Soler P, Rosenberg N, Baud F, Gervais P. Persistent asthma after inhalation of a mixture of sodium hypochlorite and hydrochloric acid. Chest 1994; 105: 1895-1896.

10. Lemière $\mathrm{C}$, Malo JL, Boutet M. Reactive airways dysfunction syndrome due to chlorine: sequential bronchial biopsies and functional assessement. Eur Respir J 1997; 10: 241-244.

11. Lemière C, Malo JL, Boulet LP, Boutet M. Reactive airways dysfunction syndrome induced by exposure to a mixture containing isocyanate: functional and histopathologic behaviour. Allergy 1996; 51: 262-265.

12. Lemière C, Malo JL, Garbe-Galanti L. Syndrome d'irritation bronchique consécutif à l'inhalation d'urée: évaluation histologique et immuno-histochimique. Bronchial irritation syndrome following inhalation of urea: histological and immunohistochemical evaluation. Rev Mal Respir 1996; 13: 595-597.

13. Demnati R, Fraser R, Plaa G, Malo JL. Histological effects of acute exposure to chlorine gas on Sprague-Dawley rats lungs. J Environ Pathol Toxicol Oncol 1995; 14: 15-19.

14. Cannon WC, Blanton EF, McDonald KE. The flow-past chamber: an improved nose-only exposure system for rodents. Am Ind Hyg Assoc J 1983; 44: 923-928.

15. Bellofiore S, Dimaria GV, Martin JG. Changes in upper and lower airway resistance after inhalation of antigen in sensitized rats. Am Rev Respir Dis 1987; 136: 363-368.

16. Martin JG, Xu LJ, Toh MY, Olivenstein R, Powell WS. Leukotrienes in bile during the early and late airway responses after allergen challenge of sensitized rats. Am Rev Respir Dis 1993; 147: 104-110.

17. Bai A, Eidelman DH, Hogg JC, et al. Proposed nomenclature for quantifying subdivisions of the bronchial wall. J Appl Physiol 1994; 77: 1011-1014.

18. Berghoff RS. The more common gases: their effect on the respiratory tract. Arch Intern Med 1919; 24: 678-684.

19. Winternitz MC. Collected studies on the pathology of war gas poisoning. New Haven, Yale University Press, 1920; pp. 1-31.

20. Deschamps D, Rosenberg N, Soler P, et al. Persistent asthma after accidental exposure to ethylene oxide. $\mathrm{Br} J$ Ind Med 1992; 49: 523-525.

21. Meulenbelt J, Dormans JAMA, Marra M, Rombout PJA, Sangster B. Rat model to investigate the treatment of acute nitrogen dioxide intoxication. Hum Exp Toxicol 1992; 11: 179-187.

22. Toya T, Serita F, Sawatari K, Fuduka K. Lung lesions induced by intratracheal instillation of nickel fumes and nickeloxide powder in rats. Ind Health 1997; 35: 69-77.

23. Wright JL, Sun J-P, Vedal S. A longitudinal analysis of pulmonary function in rats during a 12 month cigarette smoke exposure. Eur Respir J 1997; 10: 1115-1119.

24. Bellofiore S, Martin JG. Antigen challenge of sensitized rats increases airway responsiveness to methacholine. $J$ Appl Physiol 1988; 65: 1642-1646.

25. Bhérer L, Cushman R, Courteau JP, et al. Survey of construction workers repeatedly exposed to chlorine over a three to six month period in a pulpmill. II. Follow up of affected workers by questionnaire, spirometry, and assessment of bronchial responsiveness 18 to 24 months after exposure ended. Occup Environ Med 1994; 51: 225-228.

26. Härkönen H, Nordman H, Korhonen O, Winblad I. Longterm effects of exposure to sulfur dioxide. Am Rev Respir Dis 1983; 128: 890-893.

27. Rajan KG, Davies BH. Reversible airways obstruction and interstitial pneumonitis due to acetic acid. $\mathrm{Br} J$ Ind Med 1989; 46: 67-68.

28. Moore BB, Sherman M. Chronic reactive disease following acute chlorine gas exposure in an asymptomatic atopic patient. Chest 1991; 100: 855-856.

29. Beasley R, Roche WR, Roberts JA, Holgate ST. Cellular events in the bronchi in mild asthma and after bronchial provocation. Am Rev Respir Dis 1989; 139: 806-817.

30. Jeffrey PK, Wardlaw AJ, Nelson FC, Collins JV, Kay AB. Bronchial biopsies in asthma: an ultrastructural, quantitative study and correlation with hyperreactivity. Am Rev Respir Dis 1989; 140: 1745-1753.

31. Vijayan VK, Sankaran K. Relationship between lung inflammation, changes in lung function and severity of exposure in victims of Bhopal tragedy. Eur Respir J 1996; 9: 1977-1982. 